\title{
Results of a comparative study of dry ozone deposition fluxes on grasslands and forest vegetation near Lake Baikal
}

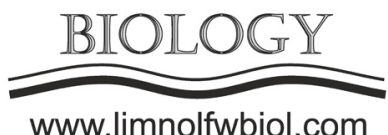

\author{
Zayakhanov A.S.*, Zhamsueva G.S., Tcydypov V.V., Balzhanov T.S., \\ Dementeva A.L., Starikov A.V.
}

Institute of Physical Materials Science, Siberian Branch of the Russian Academy of Sciences, Sakhyanovoy Str., 6, Ulan-Ude, 670047, Russia

\begin{abstract}
The purpose of this work is the experimental study of the flux and rate of the dry deposition of ozone on different types of vegetation in the Baikal region. Based on the eddy covariance method and the flux gradient methods (including the aerodynamic gradient method (AGM), the modified Bowen method (MBR) and modified gradient method (MGM)) and with experimental data, the quantitative estimates of the fluxes and dry deposition velocity of ozone on the underlying surface were obtained for different environments (grasslands, forest).
\end{abstract}

Keywords: atmosphere; dry deposition; ozone; trace gases; Baikal region

A method of gradient measurements regarding the concentration of ozone $\left(\mathrm{O}_{3}\right)$ and atmospheric dynamic characteristics with the help of meteorological masts was used to study the effect of the thermal stratification of the atmosphere on ozone, and to study the characteristics of the exchange processes of trace gases (fluxes and rates of dry deposition) between the atmosphere and the underlying surface (grasslands, forest).

The sample site is located within the territory of the Boyarsky stationary site $(51 \circ 830 \mathrm{~N}, 106.060 \mathrm{E})$ of Institute of Physical Materials Science Siberian Branch, Russian Academy of Sciences, which is situated at a distance of $500 \mathrm{~m}$ from the Baikal water area, at heights of $60 \mathrm{~m}$ from the lake level. Air samples were taken at different heights above ground level using Teflon tubes. Observations were performed using chemiluminescent gas analyzers 3-02 P-A for ozone (OPTEK Corp., St. Petersburg, Russia). Simultaneously, the meteorological and turbulent parameters of the atmosphere were measured using the acoustic meteorological complexes: AMK-03 and EXMETEO (Sibanalitpribor Ltd., Tomsk, Russia).

Atmosphere Experiments-Grasslands. To estimate the flux of ozone to the underlying surfaces, the calculations were conducted with proven methods (Erisman et al., 1994; Jacobson, 1999; Qin et al., 2004). To evaluate the flux of ozone to the underlying surfaces as a quantitative characteristic, the velocity and deposition rate of ozone are used (Equation (1)):

$$
\mathrm{F}=-\mathrm{V}_{\mathrm{d}} \times \mathrm{C}
$$

where $\mathrm{C}$ is the concentration of ${ }_{0} 3$ and ${ }_{v} d$ is the dry deposition velocity.

The dry deposition velocity is calculated by analogy with Ohm's law, considering different types of resistance to the transfer of pollutants from the atmosphere to the underlying surface (Jacobson, 1999). The dry deposition velocity for gases is the following:

$$
\mathrm{V}_{\mathrm{d}}=1 /\left(\mathrm{R}_{\mathrm{a}}+\mathrm{R}_{\mathrm{b}}+\mathrm{R}_{\mathrm{c}}\right)
$$

where ${ }_{\mathrm{R}} \mathrm{a}$ is the aerodynamic resistance to the flux of gases, ${ }_{R} b$ is the quasi-laminar sublayer resistance, and ${ }_{R} c$ is the canopy resistance (Qin et al., 2004).

At night in the atmosphere, the velocity of the dry deposition of $\mathrm{O}_{3}$ and its flux to the underlying surface are much lower than in the daytime in periods when turbulent processes are less intense. In the daytime, the processes of $\mathrm{O}_{3}$ formation dominate over the processes of its destruction, as evidenced by the increase of $\mathrm{O}_{3}$ in the daytime. At night, in the absence of UV illumination, the generation process stops and forests act as a sink for ozone.

Atmosphere Experiments-Forest. Using results of measurements of meteorological parameters, such as turbulent characteristics of temperature, wind speed, and concentration $\mathrm{O}_{3}$ at different heights, the calculations of the dry deposition velocity of ozone were conducted based on MGM (Wu et al., 2015). Applying the flux gradient theory inside the canopy of the forest,

*Corresponding author.

E-mail address: azayakhanov@gmail.com (A.S. Zayakhanov)

(C) Author(s) 2020. This work is distributed under the Creative Commons Attribution 4.0 License. 
the flux F (z) can be calculated as in Equation (3):

$$
\mathrm{F}=-\mathrm{K}_{\mathrm{c}}(\mathrm{z}) \mathrm{dC} / \mathrm{dz}
$$

where ${ }_{\mathrm{K}} \mathrm{c}(\mathrm{z})$ is the vortex diffusion and $\mathrm{dC} / \mathrm{dz}$ is the vertical gradient of the gas concentration.

The calculations were carried out using the software system Mathcad 15 (Parametric Technology Corporation, Boston, MA, USA).

In this study, to quantify the flux of $\mathrm{O}_{3}$ to the underlying surface in the Baikal region, the deposition velocity and flux of ozone values were used. For different environments (grasslands, forest) in the Baikal region, the quantitative estimates of the fluxes and rates of dry ozone deposition on the underlying surface were obtained. These preliminary assessment results were carried out based on the proven calculation methods and experimental data. For the forest environment, the average values of the dry deposition velocity of $\mathrm{O}_{3}$ were equal to $0.37 \mathrm{~cm} / \mathrm{s}$ at night $(0-3 \mathrm{~h})$ and 0.91 $\mathrm{cm} / \mathrm{s}$ during daytime hours $(12-18 \mathrm{~h})$. The ozone flux was $0.24 \mu \mathrm{g} \mathrm{m}^{-2} \mathrm{~s}^{-1}$ at night and $0.72 \mu \mathrm{g} \mathrm{m}^{-2} \mathrm{~s}^{-1}$ in the afternoon. In grasslands, the dry deposition velocity of $\mathrm{O}_{3}$ and the flux of $\mathrm{O}_{3}$ did not exceed $0.16 \mathrm{~cm} / \mathrm{s}$ and 0.08 $\mu \mathrm{g} \mathrm{m}^{-2} \mathrm{~s}^{-1}$ at night and $0.34 \mathrm{~cm} / \mathrm{s}$ and $0.21 \mu \mathrm{gm}^{-2} \mathrm{~s}^{-1}$ during daytime. The quantitative estimates of the $\mathrm{V}_{\mathrm{d}}$ and $\mathrm{F}$ on grasslands and in the forest showed the higher absorptive capacity of forests compared to grasslands.

This research was funded by State project No. AAAA-A17-117121140006-0 and partly by the Russian Foundation for Basic Research (RFBR) (grant No. 18-45-030032 $r_{-} a$ ) in the desk-based processing of experimental data and numerical calculations.

\section{References}

Erisman J.W., Van Pul A., Wyers P. 1994. Parameterization of surface resistance for the quantification of atmospheric deposition of acidifying pollutants and ozone. Atmospheric Environment 28: 2595-2607. DOI: 10.1016/1352-2310(94)90433-2

Jacobson M.Z. 1999. Fundamentals of atmospheric modeling. Cambridge: Cambridge University Press.

Qin Y., Tonnesen G.S., Wang Z. 2004. Weekend/ weekday differences of ozone, NOx, CO, VOCs, $\mathrm{PM}_{10}$ and the light scatter during ozone season in southern California. Atmospheric Environment 38: 3069-3087. DOI: 10.1016/j. atmosenv.2004.01.035

Wu Z.Y., Zhang L., Wang X.M. et al. 2015. A modified micrometeorological gradient method for estimating $\mathrm{O}_{3}$ dry depositions over a forest canopy. Atmospheric Chemistry and Physics 15: 7487-7496. DOI: 10.5194/acp-15-7487-2015 